\title{
Urinary NGAL and KIM-1 Are the Early Detecting Biomarkers of Preterm Infants with Acute Kidney Injury
}

\author{
Hongzhu Lu1,2, Qihong Fan1,2, Lu Wang1, Nipun Shrestha', Sijan Thapa1 \\ ${ }^{1}$ Department of Pediatrics, The First Clinical College, Yangtze University, Jingzhou, China \\ ${ }^{2}$ Pediatric Research Institute of Yangtze University, Jingzhou, China \\ Email: lucas215@163.com
}

How to cite this paper: Lu, H.Z., Fan, Q.H., Wang, L., Shrestha, N. and Thapa, S. (2019) Urinary NGAL and KIM-1 Are the Early Detecting Biomarkers of Preterm Infants with Acute Kidney Injury. Yangtze Medicine, 3, 183-194.

https://doi.org/10.4236/ym.2019.33019

Received: December 20, 2018

Accepted: June 25, 2019

Published: June 28, 2019

Copyright $\odot 2019$ by author(s) and Scientific Research Publishing Inc. This work is licensed under the Creative Commons Attribution International License (CC BY 4.0).

http://creativecommons.org/licenses/by/4.0/

(c) (†) Open Access

\begin{abstract}
Background: Acute kidney injury (AKI) is common in neonates. However, early diagnosis is difficult. Different biomarkers for early diagnosis of AKI, such as NGAL, KIM-1, Cys-C, IL-18, $\beta 2$-microglobulin have been proposed. But regarding premature infant, there is very little research that has been reported. Objectives: To investigate the role of urinary NGAL and Kim-1 biomarkers for early diagnosis of AKI in premature neonates. Methods: Eighty cases were divided into experimental group (60 cases) and controls group (20 cases). Of 60 cases, 24 patients met the criteria for AKI group; the remaining 36 were non-AKI group. Blood and urine samples, $1 \mathrm{ml}$ each, were collected from all subjects at first day, second day, third day and seventh day of life. Urine NGAL and KIM-1 were measured by ELISA. Results: The urinary NGAL and KIM-1 are significantly higher in AKI group than Non-AKI group and normal control group in the first three days. They present earlier than classical Scr. Conclusion: Urinay NGAL and Kim-1 are beneficial biomarkers for the early diagnosis of AKI in preterm neonates.
\end{abstract}

\section{Keywords}

Neonate, Acute Kidney Injury, NGAL, KIM-1

\section{Introduction}

Acute Kidney Injury (AKI), formerly known as Acute Renal Failure (ARF), is one of the numbers of conditions that affect kidney function and structure. AKI is currently defined as reduction in kidney function, including decreased glomerular filtration rate (GFR) and kidney failure. The change in serum creatinine 
(SCr) and urine output are the classical parameter used to diagnose severity and stage of AKI. The RIFLE criteria have been proposed by the Acute Dialysis Quality Initiative (ADQI) group, aid in the staging of patients with AKI [1] [2].

According to World Health Organization statistics, 28\% of all neonatal deaths are due to premature birth. In the past 20 years, some developed countries have preterm birth rates ranging from $5 \%$ to $7 \%$ [3]. In recent years, a series of studies have found that mortality of preterm infants is closely related to preterm infants with renal impairment [4] [5]. Premature infants are at unique risk for developing AKI due to incomplete nephrogenesis, early exposure to nephrotoxic medications (i.e. Indomethacin, Ibuprofen, cefotaxime, aminoglycosides), and coexisting conditions such as patent ductus arteriosus (PDA) and respiratory distress syndrome (RDS). AKI prevention and therapy have as of yet been rather unsuccessful and unsatisfactory [6] [7]. Serum creatinine concentrations are influenced by many factors. A significant disadvantage of these tests is the time delay between injury and detection, making the tests insensitive and unreliable for diagnostic and prognostic measurements [6]. It is suggested to use other markers which are stable over time and are not affected by muscle mass or tubular reabsorption and secretion. Specific proteins excreted in the urine after injury to particular segments of the nephron can serve as biomarkers for assessing the site and severity of renal damage [7]. Currently, for adults and children, many experts and scholars have proposed different biomarkers for early diagnosis of AKI [8], such as NGAL, KIM-1, Cys-C, etc. But regarding premature infant, there is very little research that has been reported. NGAL is a $25-\mathrm{kDa}$ protein that belongs to lipocalin group which is highly expressed in proximal tubular epithelial cells and has role in renal tubular epithelial cells formation and repair. It is expressed in neutrophils and in low levels in the kidney, prostate, and epithelia of the respiratory and alimentary tracts [9] [10]. When AKI occurs, tubular epithelial cell is damaged and blood and urine NGAL are abundantly expressed [11]. KIM-1 belongs to immunoglobulin super family. It is a type 1transmembrane glycoprotein, the mucin, immunoglobulins composition, an adhesion molecule [12]. We investigate the role of urinary NGAL and Kim-1 biomarkers for early diagnosis of $\mathrm{AKI}$ in premature neonates.

\section{Materials and Methods}

\subsection{Patients}

Eighty cases were divided into experimental group (60 cases, gastational age less than 34 weeks) and controls group (20 cases, gastational age more than 37 weeks), excluding infection, congenital malformation of the urinary system, cases of medication during pregnancy by the mother. The control group was without risk factors like abnormal pregnancy or use of nephrotoxic medication or trauma, asphyxia, congenital uninary tract malformation. Families of preterm infants involved in all the cases were informed about the study and the consent was signed. The approval of the hospital ethics committee was obtained. Record 
of all selected cases infants and their mother was maintained like inpatient number, name, sex, gestational age, birth weight, Apgar scores, gravidity and parity. Case-control data analysis was performed.

Of the 80 cases, 60 cases were the experimental group and 20 cases were the control group, according to the diagnostic criteria for acute kidney injury in 2007 the United States AKIN (within 48 hours, SCr increased to more than 26.5 $\mu \mathrm{mol} / \mathrm{L}$; or percentage increase in $\mathrm{SCr}$ by more than or equal to $50 \%$; or reduction in urine output less than $0.5 \mathrm{ml} / \mathrm{kg} /$ hour over six hours), the experimental group was divided into AKI group, the non-AKI group. Out of 60 cases, 24 patients met the criteria for AKI group; the remaining 36 were non-AKI group; the other 20 cases without any other risk factors were full-term newborns grouped as normal controls.

Blood and urine samples, $1 \mathrm{ml}$ each, was collected from all subjects at first day, second day, third day and seventh day of life. The samples were immediately centrifuged (room temperature $18^{\circ} \mathrm{C}, 3500 \mathrm{rpm}, 5 \mathrm{~min}$ ), (low speed automatic balance centrifuge, LDE5-2, Beijing, China). After centrifugation, the supernatant (serum) $100 \mu \mathrm{l}$ was kept in hospital central laboratory at $-80^{\circ} \mathrm{C}$ temperature. Blood samples were collected by conventional tube, urine specimens were collected in urine tube.

\subsection{Detection of Samples}

Nissan OLYMPUS AU5400 automatic biochemical analyzer available in our hospital laboratory was used for serum creatinine.

Urine NGAL and KIM-1 were measured by enzyme-linked immunosorbent assay (ELISA), the kit provided by Shanghai Biological Technology Co., Ltd. (SEB388Hu 96T). The procedure was followed strictly according to the kit instructions.

\subsection{Statistical Analysis}

Measurement data were expressed as mean \pm standard deviation. The comparison between the groups was done using the $\mathrm{F}$ test. Correlation between the index and serum creatinine were evaluated using linear regression. Each index sensitivity and specificity was evaluated with the area under the ROC curve. Statistical analysis was done using SPSS19.0.

\section{Results}

\subsection{Eighty Neonates Was Enrolled}

We investigated gestational ages, birth weight, and Apgar score of all cases. The summary clinical data of all neonates is illustrated in Table 1.

\subsection{AKI Group, the Non-AKI Group, Control Group of Preterm Infants of Different Age and Scr}

From Table 2, Figure 1, it is seen that for the same-day-old premature children, 


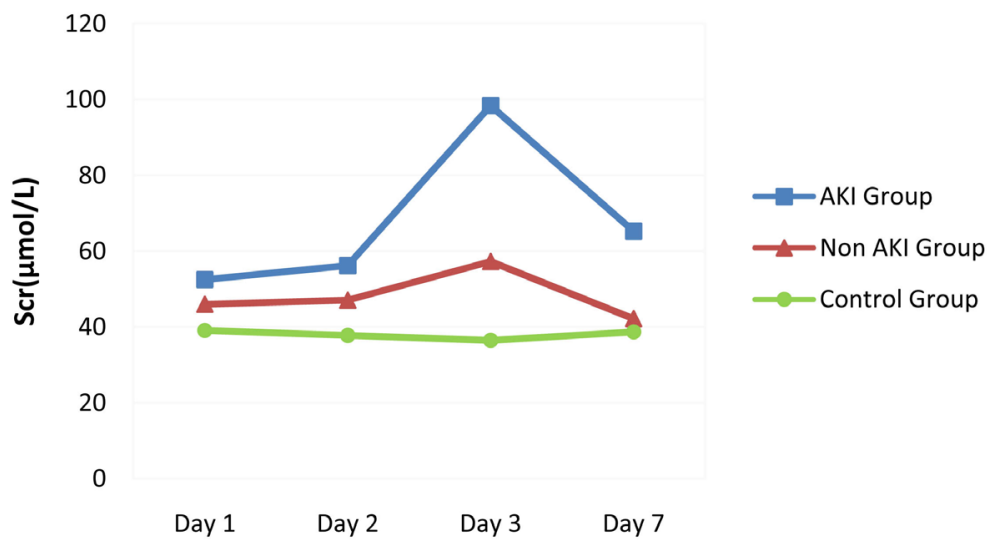

Figure 1. Changes of Scr in premature infants with different age groups.

Table 1.80 cases of neonatal clinical data.

\begin{tabular}{|c|c|c|}
\hline \multicolumn{2}{|c|}{ Clinical data } & \multirow{2}{*}{$\begin{array}{c}\text { Number of cases } \\
42 / 38\end{array}$} \\
\hline Gender & Male/Female & \\
\hline \multirow{3}{*}{ Gestational Age } & $\leq 34$ Week & 18 \\
\hline & 34 - 36 Week & 42 \\
\hline & $\geq 37$ Week & 20 \\
\hline \multirow{4}{*}{ Birth Weight } & $\leq 1.5 \mathrm{~kg}$ & 7 \\
\hline & $1.5 \mathrm{~kg}-2 \mathrm{~kg}$ (Including $2 \mathrm{~kg}$ ) & 17 \\
\hline & $2 \mathrm{~kg}-3 \mathrm{~kg}$ (Including $3 \mathrm{~kg}$ ) & 39 \\
\hline & $>3 \mathrm{~kg}$ & 24 \\
\hline \multirow{3}{*}{ Apgar 1 minute } & 0 - 3 Score (Including 3 score) & 1 \\
\hline & 4 - 7 Score (Including 7 score) & 13 \\
\hline & $>7$ Score & 66 \\
\hline \multirow{2}{*}{ Mode of Delivery } & Birth & 13 \\
\hline & Caesarean section & 67 \\
\hline
\end{tabular}

Table 2. Changes in Scr in preterm infants of different age groups $(\mu \mathrm{mol} / \mathrm{L})\left(\begin{array}{l}\bar{X} \\ \pm S\end{array}\right)$.

\begin{tabular}{cccccc}
\hline & $\mathrm{n}$ & Day 1 & Day 2 & Day 3 & Day 7 \\
\hline AKI Group (1) & 26 & $52.5 \pm 30.3$ & $56.2 \pm 27.5$ & $98.4 \pm 36.1$ & $65.3 \pm 27.5$ \\
Non AKI Group (2) & 34 & $46.0 \pm 9.4$ & $47.1 \pm 10.2$ & $57.3 \pm 18.5$ & $42.2 \pm 14.3$ \\
Normal control group (3) & 20 & $39.1 \pm 8.1$ & $37.8 \pm 7.4$ & $36.5 \pm 8.3$ & $38.7 \pm 8.8$ \\
F value & & 2.869 & 6.319 & 4.292 & 15.109 \\
P value & 0.063 & 0.003 & $<0.001$ & $<0.001$ \\
(1) (2) compare P value & & 0.186 & 0.052 & $<0.001$ & $<0.001$ \\
(1) (3) compare P value & 0.019 & 0.001 & $<0.001$ & $<0.001$ \\
(2) (3) compare P value & 0.201 & 0.061 & 0.003 & 0.512 \\
\hline
\end{tabular}


Scr is significantly high in AKI group compared to control group. This difference is statically significant. It is seen that in AKI and control group, for Scr at day $1,2,3$ and $7, \mathrm{P}<0.05$ and the difference is statically significant. For the Same-day-old premature children on the first day and second day, $\mathrm{P}>0.05$ in $\mathrm{AKI}$ and non-AKI groups, the difference is not statistically significant. At 3rd day and 7th day, $\mathrm{P}<0.05$ in AKI group and non-AKI group comparison, the difference is statistically significant. Comparing Non-AKI group and normal control, first 1, 2, 7 days $\mathrm{P}>0.05$, the first three days $\mathrm{P}<0.05$.

In the AKI group, there is no significant change in Scr in first and second day and then increases with increasing age and again decreases by seventh day. In case of Non-AKI group, each time the reading is slightly higher than those in the control group, the first decline is seen in seventh days. In the control group, from day 1 to day 7 , Scr is basically unchanged.

\subsection{Changes of NGAL in Preterm Children of Different Age Group in AKI Group, the Non-AKI Group and Control Group}

Table 3 and Figure 2 show that NGAL is significantly high in AKI group and Non-AKI group when compared to control group of the preterm child of same age. This difference is statistically significant. AKI group and non-AKI group, on days 1 to $3, \mathrm{P}<0.05$ difference was statistically significant. AKI group and the normal control group, at day 1, 2, 3, 7 days, $\mathrm{P}<0.05$ and the difference was statistically significant. Non-AKI group and normal control group, who was born the first 1, 2, 3, 7 days, $\mathrm{P}<0.05$ difference was again statistically significant. For AKI group and non-AKI group preterm children, NGAL increased with age. NGAL was on rise during the first three days and the first decline was seen slightly on the seventh day. AKI group compared with non-AKI group and normal control group, the first day there is a clear upward rise on the first two days, significantly increased on the first three days and decreased on seventh day.

Table 3. Changes in NGAL in preterm children of different age group (ng/ml) $(\bar{X} \pm S)$.

\begin{tabular}{|c|c|c|c|c|c|}
\hline & $\mathrm{N}$ & Day 1 & Day 2 & Day 3 & Day 7 \\
\hline AKI Group (1) & 26 & $2.1 \pm 1.4$ & $2.23 \pm 1.49$ & $2.58 \pm 1.51$ & $1.48 \pm 1.33$ \\
\hline Non AKI Group (2) & 34 & $1.72 \pm 1.19$ & $1.81 \pm 1.37$ & $1.87 \pm 1.38$ & $1.44 \pm 1.17$ \\
\hline Control (3) & 20 & $0.54 \pm 0.28$ & $0.66 \pm 0.45$ & $0.83 \pm 0.90$ & $0.67 \pm 0.60$ \\
\hline F value & & 11.494 & 9.302 & 9.892 & 3.731 \\
\hline $\mathrm{P}$ value & & $<0.001$ & $<0.001$ & $<0.001$ & 0.028 \\
\hline (1) (2) compare P & & 0.039 & 0.041 & 0.042 & 0.035 \\
\hline (1) (3) compare $\mathrm{P}$ & & $<0.001$ & $<0.001$ & $<0.001$ & 0.017 \\
\hline (2) (3) compare P & & $<0.001$ & 0.002 & 0.007 & 0.016 \\
\hline
\end{tabular}




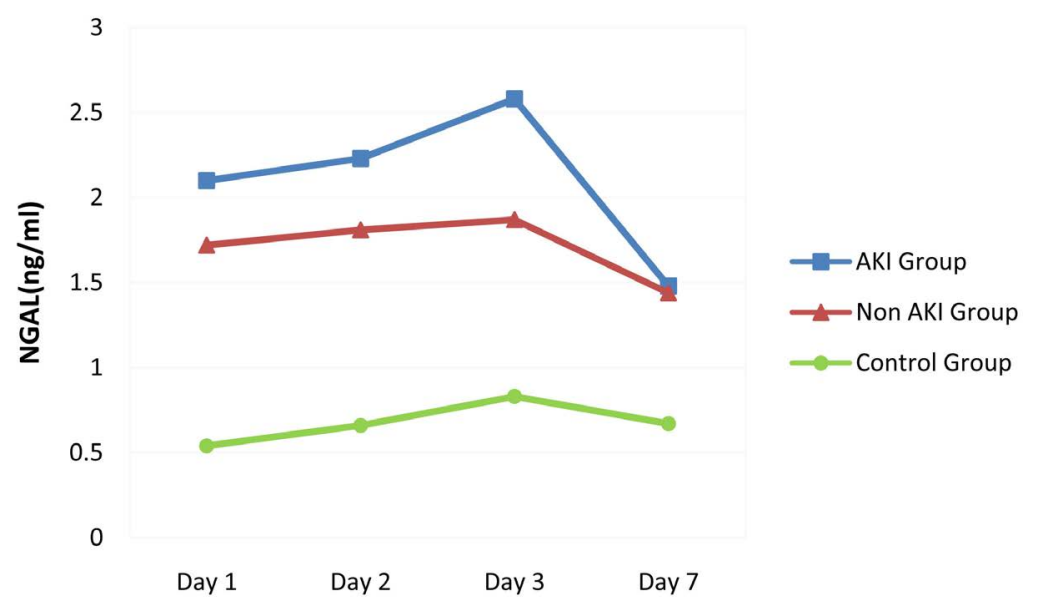

Figure 2. Changes of NGAL in preterm at different ages.

\subsection{KIM-1 in AKI Group, Non-AKI Group, Control Group of Preterm Infants Different Ages}

Table 4 and Figure 3 show that KIM-1 is significantly high in AKI group and Non-AKI group when compared to control group of the preterm child of same age. This difference is statistically significant. AKI group and non-AKI group, on days 1 to $7, \mathrm{P}<0.05$ difference was statistically significant. AKI group and the normal control group, at day 1, 2, 3, 7 days, $\mathrm{P}<0.05$ and the difference was statistically significant. Non-AKI group and normal control group, was born the first 1, 2, 3, 7 days, $P>0.05$ difference was statistically not significant.

For AKI group and non-AKI group preterm children, KIM-1 increased with age. KIM-1 was on rise during the first three days and then decline was seen slightly on the seventh day. AKI group compared with non-AKI group and normal control group, the first day there is a clear upward rise on the first two days, significantly increased on the first three days and decreased on seventh day.

\section{Discussion}

The potential role of urine protein biomarkers to detect kidney damage are an area of active investigation. The present study showed that the urinary NGAL and KIM-1 are significantly higher in AKI group than Non-AKI group and normal control group in the first three days. They present earlier than classical Scr. So the urinay NGAL and Kim-1 are benifical biomarkers for the early diagnosis of AKI in preterm neonates.

In the case of AKI, NGAL is secreted in high levels into the blood and urine within 2 hours of injury [13]. Urinary NGAL appears to be the most promising AKI biomarker and it is the most strikingly upregulated gene and overexpressed protein in the kidney after ischemia [14].

The NGAL level measured in an individual is proportional to the severity of the AKI [15]. Renal expression of NGAL increases in the kidneys after injury for a variety of reasons. Many studies have evaluated urinary and serum NGAL 


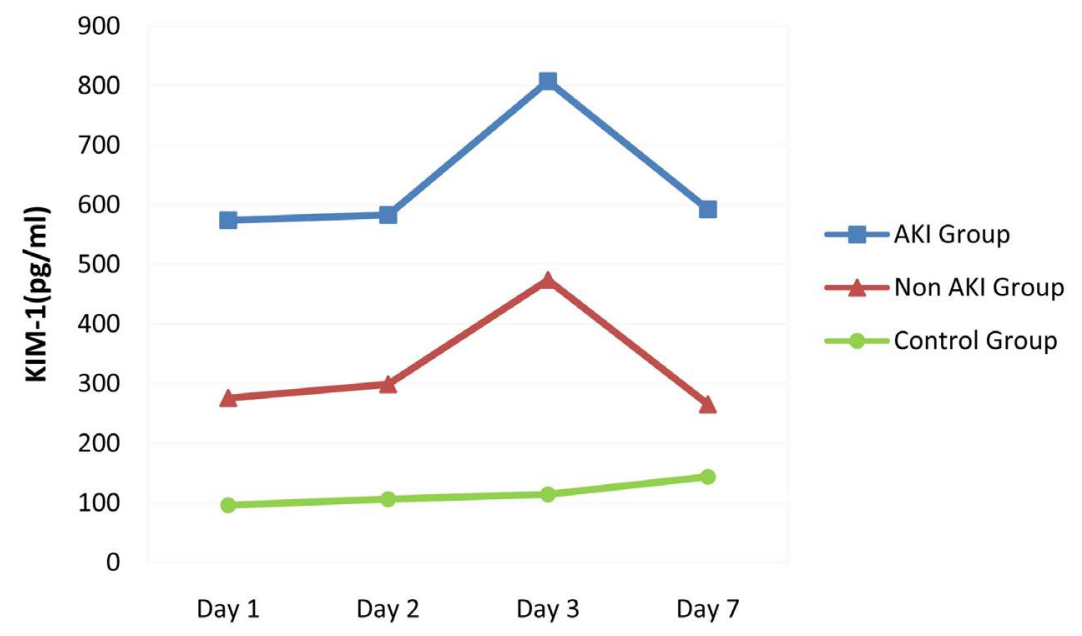

Figure 3. Changes of KIM-1 in premature infants of different age groups.

Table 4. Preterm children of different age groups and KIM-1 (ng/ml) ( $\bar{X} \pm \mathrm{S})$.

\begin{tabular}{cccccc}
\hline & $\mathrm{n}$ & Day 1 & Day 2 & Day 3 & Day 7 \\
\hline AKI Group (1) & 26 & $574.1 \pm 562.1$ & $583 \pm 896.4$ & $807.3 \pm 1344$ & $592.5 \pm 806.2$ \\
Non AKI Group (2) & 34 & $276 \pm 306$ & $299 \pm 328.2$ & $473.9 \pm 688.4$ & $265.4 \pm 294.3$ \\
Control (3) & 20 & $95.96 \pm 59.17$ & $106.2 \pm 80.9$ & $114.0 \pm 69.5$ & $143.6 \pm 106.6$ \\
F value & & 9.553 & 4.346 & 3.445 & 5.216 \\
P value & $<0.001$ & 0.016 & 0.037 & 0.008 \\
(1) (2) compare P & 0.003 & 0.045 & 0.048 & 0.014 \\
(1) (3) Compare P & & $<0.001$ & 0.005 & 0.011 & 0.004 \\
(2) (3) Compare P & 0.096 & 0.221 & 0.155 & 0.391 \\
\hline
\end{tabular}

capacity to predict AKI in both adults [16] [17] and older children [18] [19]. NGAL in children and newborn range has been relatively a widespread concern. A study on children with pediatric cardiopulmonary bypass operations showed that urinary NGAL concentrations above $50 \mathrm{ng} / \mathrm{mL}$ in 2 hours after surgery and serum creatinine levels $50 \%$ over basal values. Normally, children tend to have almost undetectable levels of NGAL [20]. Hundreds of clinical studies demonstrate that NGAL measures kidney injury but the studies are mainly done in adult population and very few studies were done in pediatric population. Lavery et al. [21] studied 20 children with low birth weight, weighing from $500 \mathrm{~g}$ to $1500 \mathrm{~g}$ and collected their urine for first 2 week of life and concluded that urine NGAL can be easily obtained in premature infants. Specifically in the neonatal population, serum and urine NGAL were evaluated in patients after Cardiopulmonary Bypass (CPB) surgery [20]. Plasma and serum NGAL collected 2 hours after $\mathrm{CPB}$ were able to predict AKI with a sensitivity and specificity of nearly $90 \%$. Another study evaluated urinary NGAL at day 1 in preterm infants and after full adjustment for other factors; it remained significantly associated with AKI development [22]. A recent study on AKI in preterm infants concluded that 
urinary NGAL may be very useful to predict AKI development prior to changes in serum creatinine in preterm infants [23]. The study found that NGAL level was much higher in AKI group than in non-AKI group. In non-AKI group, the level of NGAL in control group was $0.598 \mu \mathrm{g} / \mathrm{ml}$ whereas in AKI group it was found to be as high as $4.24 \mu \mathrm{g} / \mathrm{ml}$. This study was performed on preterm infants below 32 weeks of gestation age. Oncel NY et al. [24] studied 41 cases of newborn with a diagnosis of perinatal asphyxia and classified the cases into AKI and non-AKI groups. The AKI group included 15 newborns and Non-AKI group included 26 newborns. The biomarker NGAL was measured on day 1 and day 4. The study concluded that urinary NGAL was higher in patients with AKI on day as well as day 4 and it can be used as an important diagnostic biomarker in such patients. Our results showed the same significance with the above.

KIM-1, under normal physiological conditions, did not increase or increase in low amount but expression was significantly increased in ischemic or nephrotoxic injury [25] [26]. The KIM-1 is stable in the urine for prolonged periods of time and can be detected in the kidney and urine in a number of nephrotoxic models in animals [27] [28] and in humans with AKI [29]. During proximal tubular damage KIM-1 can be detected in urine, in the form of a soluble fragment, stable nature [30] [31]. Han et al. demonstrated marked expression of KIM-1 in kidney biopsy specimens from six patients with acute tubular necrosis, and found elevated urinary levels of KIM-1 after an initial ischemic renal insult, prior to the appearance of casts in the urine [12]. A longitudinal prospective study conducted by van Timmeren et al. [32] reported that elevated urinary KIM-1 serves as an independent predictor of long-term graft loss in renal transplant recipients ( $\mathrm{n}=145$ patients) independent of donor age, creatinine clearance and proteinuria.

Sabbisetti VS et al. [33], conducted a study on ischemia reperfusion in mice and found that there are significant expression of KIM-1 for 12 hours before Scr increased. Sprenkle P et al. [34] found that, in the event of tissue ischemia, by detecting Scr alone prediction of early AKI was missed. The KIM-1 has a value of early diagnosis. Mihye Jeong et al. [35], studied drug-induced renal toxicity in rats and found that KIM-1 has important significance in early detection of AKI with high sensitivity. Song L et al. [36], studied on 69 patients after renal transplantation and found that increasing the tubular cell damage and the extent of renal injury and KIM-1 levels were positively correlated. Van Timmeren MM et al. [37] studied in 109 cases with biopsy specimens, of which 102 cases have kidney injury and seven cases of normal controls. Urinary KIM-1 was measured by ELISA, the study found that KIM-1 was highly expressed in proximal tubules. KIM-1 can be used as non-invasive biomarker of kidney injury. Tubular KIM-1 levels are virtually undetectable in healthy kidney tissues but are markedly increased after injury to the kidney [12]. Lee HE et al. [38], demonstrated significance expression of KIM-1 on cohort study of infants with febrile urinary tract infection that suggest renal injujry. 
Zwiers AJ et al. [39] conducted a prospective observational cohort study of 100 term-born infants ages 1 day to 1 year on mechanical ventilation. Thirty-five patients had evidence of AKI within the first 48 hours post-admission, of whom 24 (69\%) already had AKI when they entered the PICU. KIM-1 concentrations in AKI peaked between 6 to 12 hours and between 12 to 24 hours post-admission. Gurkan Genc et al. [40] studied in 48 premature babies hospitalized in the neonatal intensive care unit were included in the study and divided into three groups: group I, healthy premature infants; group II, preterm infants with RDS without AKI; group III, preterm infants with RDS and AKI. Urinary KIM-1 along with Scr levels were measured with ELISA on days 1, 3, and 7 of life. On day 1 babies with RDS and AKI, KIM-1 were higher than the other two groups. Nephrotoxicity is a common side effect of therapeutic interventions, environmental insults, and exposure to toxicants. Although biomarkers for nephrotoxicity are available, they often lack sensitivity and are not specific as indicators of epithelial cell injury [41] [42]. Urinary KIM-1 expression may be detected after exposure to a variety of nephrotoxic agents, even when serum creatinine concentrations do not increase, and this has been accepted by regulatory authorities as a sensitive biomarker of AKI [43]. We also found that urinary KIM-1 is a very sensitive biomarker in neonates with AKI.

Our study results indicated that both NGAL and KIM-1 are more sensitive and easier to detect for the neonates with AKI than Scr.

\section{Conclusion}

AKI is vital for the neonates, especially preterm neonates. Early diagnosis is critical for the treatment and better prognosis. Our study showed that urinay NGAL and KIM-1 are beneficial and easier biomarkers for the early diagnosis of AKI in preterm neonates. However, further investigation that whether these biomarkers can predict the clinical outcome is indicated. Larger samples of preterm neonates with different courses of AKI are needed.

\section{Conflicts of Interest}

The authors declare no conflicts of interest regarding the publication of this paper.

\section{References}

[1] Bellomo, R., Ronco, C., Kellum, J.A., et al. (2004) Acute Renal Failure-Definition, Outcome Measures, Animal Models, Fluid Therapy and Information Technology Needs: The Second International Consensus Conference of the Acute Dialysis Quality Initiative (ADQI) Group. Critical Care, 8, R204-R212.

[2] Lameire, N., Van Biesen, W. and Vanholder, R. (2005) Acute Renal Failure. The Lancet, 365, 417-430. https://doi.org/10.1016/S0140-6736(05)70238-5

[3] Beck, S., Wojdyla, D., Say, L., et al. (2010) The Worldwide Incidence of Preterm Birth: A Systematic Review of Maternal Mortality and Morbidity. Bulletin of the World Health Organization, 88, 31-38. https://doi.org/10.2471/BLT.08.062554 
[4] Walker, M.W., Clark, R.H. and Spitzer, A.R. (2011) Elevation in Plasma Creatinine and Renal Failure in Premature Neonates without Major Anomalies: Terminology, Occurrence and Factors Associated with Increased Risk. Journal of Perinatology, 31, 199-205. https://doi.org/10.1038/jp.2010.82

[5] Csaicsich, D., Russo-Schlaff, N., Messerschmidt, A., Weninger, M., Pollak, A. and Aufricht, C. (2008) Renal Failure, Comorbidity and Mortality in Preterm Infants. Wiener Klinische Wochenschrift, 120, 153-157. https://doi.org/10.1007/s00508-008-0941-5

[6] Sweetman, D.U. (2017) Neonatal Acute Kidney Injury-Severity and Recovery Prediction and the Role of Serum and Urinary Biomarkers. Early Human Development, 105, 57-61. https://doi.org/10.1016/j.earlhumdev.2016.12.006

[7] Harrill, A.H., Lin, H., Tobacyk, J. and Seely, J.C. (2018) Mouse Population-Based Evaluation of Urinary Protein and miRNA Biomarker Performance Associated with Cisplatin Renal Injury. Experimental Biology and Medicine, 243, 237-247. https://doi.org/10.1177/1535370217740854

[8] Askenazi, D.J., Koralkar, R., Letivan, E.B., et al. (2011) Baseline Values of Candidate Urine Acute Kidney Injury (AKI) Biomarkers Vary by Gestational Age in Premature Infants. Pediatric Research, 70, 302-306. https://doi.org/10.1203/PDR.0b013e3182275164

[9] Cowland, J.B. and Borregaard, N. (1997) Molecular Characterization and Pattern of Tissue Expression of the Gene for Neutrophil Gelatinase-Associated Lipocalin from Humans. Genomics, 45, 17-23. https://doi.org/10.1006/geno.1997.4896

[10] Friedl, A., Stoesz, S.P., Buckley, P. and Gould, M.N. (1999) Neutrophil Gelatinase-Associated Lipocalin in Normal and Neoplastic Human Tissues. Cell Type-Specific Pattern of Expression. The Histochemical Journal, 31, 433-441. https://doi.org/10.1023/A:1003708808934

[11] Dagher, P.C., Herget-Rosenthal, S., Ruehm, S.G., Jo, S.-K., Star, R.A., et al. (2003) Newly Developed Techniques to Study and Diagnose Acute Renal Failure. Journal of the American Society of Nephrology, 14, 2188-2198. https://doi.org/10.1097/01.ASN.0000079790.91292.4A

[12] Han, W.K., Bailly, V., Abichandani, R., et al. (2002) A Novel Biomarker for Human Renal Proximal Tubule Injury. Kidney International, 62, 237-244. https://doi.org/10.1046/j.1523-1755.2002.00433.x

[13] Bennett, M., Dent, C.L., Ma, Q., et al. (2008) Urine NGAL Predicts Severity of Acute Kidney Injury after Cardiac Surgery: A Prospective Study. Clinical Journal of the American Society of Nephrology, 3, 665-673. https://doi.org/10.2215/CJN.04010907

[14] Mishra, J., Qing, M.N., Prada, A., Mitsnefes, M., Zahedi, K., et al. (2003) Identification of Neutrophil Gelatinase-Associated Lipocalin as a Novel Early Urinary Biomarker for Ischemic Renal Injury. Journal of the American Society of Nephrology, 14, 2534-2543. https://doi.org/10.1097/01.ASN.0000088027.54400.C6

[15] Haase, M., Devarajan, P., Haase-Fielitz, A., et al. (2011) The Outcome of Neutrophil Gelatinase-Associated Lipocalin-Positive Subclinical Acute Kidney Injury: A Multicenter Pooled Analysis of Prospective Studies. Journal of the American College of Cardiology, 57, 1752-1761. https://doi.org/10.1016/j.jacc.2010.11.051

[16] Lippi, G., Aloe, R., Storelli, A., Cervellin, G. and Trenti, T. (2012) Evaluation of NGAL Test, a Fully-Automated Neutrophil Gelatinase-Associated Lipocalin (NGAL) Immunoassay on Beckman Coulter AU 5822. Clinical Chemistry and Laboratory Medicine, 50, 1581-1584. https://doi.org/10.1515/cclm.2011.839

[17] Wagener, G., Gubitosa, G., Wang, S., Borregaard, N., Kim, M. and Lee, H.T. (2008) 
Urinary Neutrophil Gelatinase Associated Lipocalin and Acute Kidney Injury after Cardiac Surgery. American Journal of Kidney Diseases, 52, 425-433. https://doi.org/10.1053/j.ajkd.2008.05.018

[18] Di Grande, A., Giuffrida, C., Carpinteri, G., et al. (2009) Neutrophil Gelatinase-Associated Lipocalin: A Novel Biomarker for the Early Diagnosis of Acute Kidney Injury in the Emergency Department. European Review for Medical and Pharmacological Sciences, 13, 197-200.

[19] Parikh, C.R., Devarajan, P., Zappitelli, M., et al. (2011) Postoperative Biomarkers Predict Acute Kidney Injury and Poor Outcomes after Pediatric Cardiac Surgery. Journal of the American Society of Nephrology, 22, 1737-1747. https://doi.org/10.1681/ASN.2010111163

[20] Krawczeski, C.D., Woo, J.G., Wang, Y., Bennett, M.R., Ma, Q. and Devarajan, P. (2011) Neutrophil Gelatinase-Associated Lipocalin Concentrations Predict Development of Acute Kidney Injury in Neonates and Children after Cardiopulmonary Bypass. The Journal of Pediatrics, 158, 1009-1015. https://doi.org/10.1016/j.jpeds.2010.12.057

[21] Lavery, A.P., Meinzen-Derr, J.K., Anderson, E., et al. (2008) Urinary NGAL in Premature Infants. Pediatric Research, 64, 423-428. https://doi.org/10.1203/PDR.0b013e318181b3b2

[22] Tabel, Y., Elmas, A., Ipek, S., Karadag, A., Elmas, O. and Ozyalin, F. (2014) Urinary Neutrophil Gelatinase-Associated Lipocalin as an Early Biomarker for Prediction of Acute Kidney Injury in Preterm Infants. American Journal of Perinatology, 31, 167-174. https://doi.org/10.1055/s-0033-1343770

[23] Hanna, M., Brophy, P.D., Giannone, P.J., et al. (2016) Early Urinary Biomarkers of Acute Kidney Injury in Preterm Infants. Pediatric Research, 80, 218-223. https://doi.org/10.1038/pr.2016.70

[24] Oncel, M.Y., Canpolat, F.E., Arayici, S., Joshi, M.S., Bauer, J.A. and Rao, S.R. (2016) Urinary Markers of Acute Kidney Injury in Newborns with Perinatal Asphyxia. Renal Failure, 38, 882-888. https://doi.org/10.3109/0886022X.2016.1165070

[25] Cruz, D.N., Goh, C.Y., Haase-Fielitz, A., Ronco, C. and Haase, M. (2010) Early Biomarkers of Renal Injury. Congestive Heart Failure, 16, 25-31.

https://doi.org/10.1111/j.1751-7133.2010.00163.x

[26] Dieterich, C., Puey, A., Lin, S., et al. (2009) Gene Expression an Alysis Reveals New Possible Mechanisms of Vancomycin Induced Nephrotoxicity and Identifies Gene Markers Candidates. Toxicological Sciences, 107, 258-269. https://doi.org/10.1093/toxsci/kfn203

[27] Amin, R.P., Vickers, A.E., Sistare, F., et al. (2004) Identification of Putative Gene Based Markers of Renal Toxicity. Environmental Health Perspectives, 12, 465-479. https://doi.org/10.1289/ehp.6683

[28] Ichimura, T., Hung, C.C., Yang, S.A., et al. (2004) Kidney Injury Molecule-1: A Tissue and Urinary Biomarker for Nephrotoxicant-Induced Renal Injury. American Journal of Physiology-Renal Physiology, 286, F552-F563. https://doi.org/10.1152/ajprenal.00285.2002

[29] Han, W.K. and Bonventre, J.V. (2004) Biologic Markers for the Early Detection of Acute Kidney Injury. Current Opinion in Critical Care, 10, 476-482. https://doi.org/10.1097/01.ccx.0000145095.90327.f2

[30] Zhang, P.L., Rothblum, L.I., Han, W.K., Blasick, T.M., Potdar, S. and Bonventre, J.V. (2008) Kidney Injury Molecule-1 Expression in Transplant Biopsies Is a Sensitive Measure of Cell Injury. Kidney International, 73, 608-614. 
https://doi.org/10.1038/sj.ki.5002697

[31] Vaidya, V.S., Ramirez, V., Ichimura, T., et al. (2006) Urinary Kidney Injury Molecule-1: A Sensitive Quantitative Biomarker for Early Detection of Kidney Tubular Injury. American Journal of Physiology-Renal Physiology, 290, 517-529. https://doi.org/10.1152/ajprenal.00291.2005

[32] Van Timmeren, M.M., Vaidya, V.S., van Ree, R.M., et al. (2007) High Urinary Excretion of Kidney Injury Molecule-1 Is an Independent Predictor of Graft Loss in Renal Transplant Recipients. Transplantation, 84, 1625-1630. https://doi.org/10.1097/01.tp.0000295982.78039.ef

[33] Sabbisetti, V.S., Ito, K., Wang, C., Yang, L., Mefferd, S.C. and Bonventre, J.V. (2013) Novel Assays for Detection of Urinary KIM-1 in Mouse Models of Kidney Injury. Toxicological Sciences, 131, 13-25. https://doi.org/10.1093/toxsci/kfs268

[34] Sprenkle, P. and Russo, P. (2013) Molecular Markers for Ischemia, Do We Have Something Better than Creatinine and Glomerular Filtration Rate. Archivos Españoles de Urología, 66, 99-114.

[35] Jeong, M., Kim, Y.W., Min, J.R., et al. (2013) Kidney Toxicity Induced by 13 Weeks Exposure to the Fruiting Body of Paecilomyces sinclairii in Rats. Toxicological Research, 28, 179-185. https://doi.org/10.5487/TR.2012.28.3.179

[36] Song, L., Xue, L., Yu, J., et al. (2013) Kidney Injury Molecule-1 Expression Is Closely Associated with Renal Allograft Damage. Bosnian Journal of Basic Medical Sciences, 13, 170-174. https://doi.org/10.17305/bjbms.2013.2357

[37] Van Timmeren, M.M., Van den Heuvel, M.C., Bailly, V., et al. (2007) Tubular Kidney Injury Molecule-1 (KIM-1) in Human Renal Disease. The Journal of Pathology, 212, 209-217. https://doi.org/10.1002/path.2175

[38] Lee, H.E., Kim do, K., Kang, H.K. and Park, K. (2015) The Diagnosis of Febrile Urinary Tract Infection in Children May Be Facilitated by URINARY Biomarkers. Pediatric Nephrology, 30, 123-130. https://doi.org/10.1007/s00467-014-2905-5

[39] Zwiers, A.J., de Wildt, S.N., van Rosmalen, J., et al. (2015) Urinary Neutrophil Gelatinase-Associated Lipocalin Identifies Critically Ill Young Children with Acute Kidney Injury Following Intensive Care Admission: A Prospective Cohort Study. Critical Care, 19, 181. https://doi.org/10.1186/s13054-015-0910-0

[40] Genc, G., Ozkaya, O., Avci, B., et al. (2004) Kidney Injury Molecule-1 as a Promising Biomarker for Acute Kidney Injury in Premature Babies. American Journal of Physiology-Renal Physiology, 286, F552-F563.

[41] Muramatsu, Y., Tsujie, M., Kohda, Y., et al. (2002) Early Detection of Cysteine Rich Protein 61 (CYR61, CCN1) in Urine Following Renal Ischemic Reperfusion Injury. Kidney International, 62, 1601-1610. https://doi.org/10.1046/j.1523-1755.2002.00633.x

[42] Price, R.G. (2000) Urinalysis to Exclude and Monitor Nephrotoxicity. Clinica Chimica Acta, 297, 173-182. https://doi.org/10.1016/S0009-8981(00)00244-8

[43] Waring, W.S. and Moonie, A. (2011) Earlier Recognition of Nephrotoxicity Using Novel Biomarkers of Acute Kidney Injury. Clinical Toxicology, 49, 720-728. https://doi.org/10.3109/15563650.2011.615319 